\title{
Desempenho do ELISA no diagnóstico da cisticercose utilizando bovinos experimentalmente e naturalmente infectados com 0 metacestódeo de Taenia saginata
}

\section{Performance of the ELISA test for the diagnosis of cysticercosis using experimentally and naturally cattle infected with metacestode of Taenia saginata}

\author{
Rafaella Paola Meneguete dos Guimarães-Peixoto ${ }^{1 *}$; Paulo Sérgio de Arruda \\ Pinto $^{2}$; Luís Augusto Nero; Tatiane de Oliveira Santos ${ }^{3}$; Letícia Ferreira da Silva ${ }^{3}$; \\ Emílio Campos Acevedo-Nieto ${ }^{3}$; Anselmo Vasconcelos Rivetti Júnior ${ }^{4}$
}

\begin{abstract}
Resumo
O complexo teníase-cisticercose bovina pode ser definido como um conjunto de alterações patológicas causadas pela forma adulta da Taenia saginata no humano e por sua forma larvar nos bovinos (Cysticercus bovis). Dados sobre a ocorrência da cisticercose bovina provêm dos registros de inspeção veterinária de carnes em matadouros-frigoríficos inspecionados, onde alguns casos positivos podem passar despercebidos, principalmente em infecções moderadas, tornando-se relevante a utilização de testes sorológicos com maior sensibilidade que o exame post-mortem de rotina. Estudos demonstram a possível aplicação do teste ELISA como ferramenta para estudos epidemiológicos da parasitose e na identificação dos animais portadores de cistos. O objetivo do presente trabalho foi avaliar o desempenho e determinar o limiar de detecção de um ELISA indireto, utilizando animais experimentalmente e naturalmente infectados na detecção de casos de cisticercose. A sensibilidade do teste para animais naturalmente infectados utilizando o ponto de corte 1 e 2 adicionados de 2 SD foi de $12 \%$ e $24,4 \%$ respectivamente. Contudo quanto utilizado o ponto de corte 1 e 2 adicionados de $3 \mathrm{SD}$ a sensibilidade do teste teve uma queda, representado $1,99 \%$ e $14,4 \%$. Já para as amostras de animais experimentalmente infectados utilizando o ponto de corte 1 e 2 adicionados de 2 SD, a sensibilidade ficou em 55,9\% e 92,5\% e adicionando 3 SD foram encontrados os valores de $31,2 \%$ e $86 \%$ respectivamente. A especificidade do teste em todas as situações testadas ficou em 100\%. É importante levar em consideração a escolha certa dos soros-controle utilizados no teste ELISA, visto que de acordo com sua aplicação torna-se necessário elevar a sensibilidade ou especificidade do teste.
\end{abstract}

Palavras-chave: Taenia saginata, ELISA, cisticercose bovina, ponto de corte

\footnotetext{
Abstract

The bovine taeniasis-cysticercosis complex can be defined as a set of pathological changes caused by the adult form of Taenia saginata in humans and their larval form in animals (Cysticercus bovis).

1 Discente de Doutorado, Pós Graduação em Medicina Veterinária, Universidade Federal de Viçosa, UFV, Viçosa, MG. E-mail: rafinhapaola@hotmail.com

2 Profs., Dept ${ }^{\circ}$ de Veterinária, UFV, Viçosa, MG. E-mail: pintopsa@ufv.br; nero@ufv.br

3 Discentes de Doutorado, Pós Graduação em Medicina Veterinária, UFV, Viçosa, MG. E-mail: tatyvetoli@hotmail.com; leticiaafs@gmail.com; ecanieto@yahoo.com.br

4 Fiscal Federal Agropecuário, Ministério da Agricultura, Pecuária e Abastecimento, Laboratório Nacional Agropecuário, Pedro Leopoldo, MG. E-mail: anselmo.rivetti@agricultura.gov.br

Autor para correspondência
} 
Data on the occurrence of bovine cysticercosis comes from the records of veterinary inspection of meat in slaughterhouses under fiscalization, where some positive cases may go unnoticed, especially in moderate infections. So, it is relevant the use of serological tests that have greater sensitivity than the post-mortem routine exams. Studies have shown the possible application of the ELISA test as a tool for epidemiological studies of the parasitosis and in the identification of animals with cysts. The aim of this study is to determine the detection threshold of the indirect ELISA test, using experimentally and naturally infected animals in detecting cases of cysticercosis. The sensitivity of the test to naturally infected animals using a cut-off 1 and 2 added with 2 standart-deviation (SD) was of $12 \%$ and 24.4\%, respectively. However, when using the cut-off of 1 and 2 added with $3 \mathrm{SD}$, the test sensitivity dropped, represented by $14.4 \%$ and $1.99 \%$ of the test sensitivity. As for the samples from experimentally infected animals, using the cut-off 1 and 2 added with 2 SD the sensitivity was $55.9 \%$ and $92.5 \%$; and adding 3 SD the values found were $31.2 \%$ and $86 \%$, respectively. The specificity of the test in all situations tested was $100 \%$. It is important to take into account the right choice of control sera used in the ELISA test, whereas, according to its application, it is necessary to increase the sensitivity or specificity.

Key words: Taenia saginata, ELISA, bovine cysticercosis, cut-off

\section{Introdução}

A cisticercose bovina é causada pela Taenia saginata, que em sua formar larvar está presente na musculatura de bovinos e na forma adulta se alberga no intestino delgado dos humanos, causando-lhes a teníase (SILVA, 2005). Sua prevalência é maior em regiões de baixo nível socioeconômico (QUEIROZ et al., 2000).

Atualmente é a zoonose que mais causa condenações em carcaças de bovinos (ROSSI et al., 2014). Os prejuízos que acarretam estão relacionados às perdas econômicas pelas partes envolvidas com o comércio de carnes (REZENDE et al., 2006), e também à saúde da população que pode se infectar com o parasito através de consumo de carnes cruas ou que não sofreram o tratamento térmico adequado, que contenham cisticercos viáveis. Guimarães-Peixoto et al. (2012) estimaram prejuízos advindos da condenação por cisticercose em torno de R\$ 119.626.428,00 analisando o período de 2004 a 2008, no Estado do Paraná.

A rotina da inspeção sanitária de carnes é a opção mais comum utilizada para o diagnóstico da cisticercose bovina, estabelecida no artigo 176 do Regulamento de Inspeção Industrial e Sanitária de Produtos de Origem Animal (RIISPOA) (BRASIL, 1997). Esse diagnóstico consiste no exame anátomopatológico dos músculos da carcaça e outros tecidos específicos, como: músculos masséteres e pterigóideos externos e internos, língua, coração e diafragma.

A inspeção de carnes por si só não permite detectar todos os cisticercos presentes nas carnes, visto que por razões de natureza estética e comercial, o inspetor normalmente não retalha todos os órgãos, vísceras e carcaças submetidas à inspeção de rotina ou posteriormente a ela, o que pode acarretar numa subestimação da real prevalência da doença (FERNANDES, 2002).

Allepuz et al. (2012) detectaram antígeno circulante por meio do teste ELISA em 23 de 2073 bovinos abatidos na região Nordeste da Espanha, obtendo uma soroprevalência de $1,11 \%$ sendo que, o valor alcançado pelo teste ELISA foi cinqüenta vezes maior do que o valor estimado pela inspeção visual ao analisar 90.891 animais nos mesmos matadouros. Ressaltando que, nenhum animal detectado como positivo pelo teste ELISA foi diagnosticado com cisticercose durante inspeção post-mortem de rotina.

Geerts et al. (1981) afirmaram que para o diagnóstico da cisticercose, é necessária uma técnica de elevada sensibilidade, devido ao alto grau de adaptação da larva de Taenia saginata ao hospedeiro, que resulta em uma baixa produção de anticorpos. Baixos níveis de anticorpos produzidos em infecções leves muitas vezes dificultam na seleção de um ponto de corte e na interpretação dos achados 
em testes sorológicos como o ELISA (SMITH; SNOWDON; FINLAY, 1991). O desenvolvimento de anticorpos anti-cisticercose é dependente, no mínimo, da magnitude da infecção estabelecida, e talvez também da fase de infecção em que os animais se encontram quando são testados (SMITH et al., 1990), sendo que, em animais naturalmente infectados a resposta imunológica tende a ser mais branda do que em animais experimentalmente infectados (KYVSGAARD et al., 1991; SMITH; SNOWDON; FINLAY, 1991; MONTEIRO, 2004; THOMAZ-SOCCOL et al., 2010).

Entretanto, o aperfeiçoamento de métodos diagnósticos modernos, como o teste ELISA, poderia melhorar esta eficiência de diagnóstico da doença, alcançando ainda os animais vivos (OGUNREMI; BENJAMIN, 2010). Diversos autores relatam a necessidade de se pesquisar e implementar o teste ELISA como método auxiliar à inspeção visual de rotina, buscando maior eficiência no diagnóstico da cisticercose bovina (QUEIROZ et al., 2000; MINOZZO et al., 2004; MONTEIRO et al., 2008). A utilização do teste ELISA revela que a prevalência da cisticercose bovina, realizada por meio de detecção através da inspeção clássica realizada em matadouros-frigoríficos é subestimada (DORNY et al., 2000), pois o exame de rotina anátomo-patológico é um método considerado de baixa sensibilidade, especialmente em infecções leves (BAVIA et al., 2012; PAULAN et al., 2013).

O teste ELISA vem sendo utilizado no diagnóstico da cisticercose em seres humanos, em suínos e bovinos, com poucos registros de sua aplicação nesses últimos, carecendo de protocolos padronizados para esta espécie, que permitam esclarecer a sua eficiência no diagnóstico da doença (PINTO; MONTEIRO; MINOZZO, 2006). O custo de implementação de uma ferramenta mais sensível para o diagnóstico da cisticercose bovina deve ser relacionado com os benefícios de uma redução riscos de infecção humana, tendo alto potencial para impedir o ciclo de transmissão da cisticercose bovina, beneficiando também o setor pecuário através de redução das perdas econômicas (ALLEPUZ et al., 2012).

Tendo em vista os fatores expostos acima, objetivou-se no presente estudo avaliar o desempenho de um ELISA indireto e determinar as taxas de sensibilidade e especificidade a partir da comparação com amostras de soro de animais não infectados, infectados naturalmente e experimentalmente com ovos de $T$. saginata, bem como comparar com o desempenho do diagnóstico de rotina de inspeção post-mortem (anátomopatológico).

\section{Material e Métodos}

\section{Infecção experimental}

Um paciente positivo para teníase foi identificado através de exame coproparasitológico (Kato Katz) em Posto de Saúde no Município de TumiritingaMinas Gerais e após tratamento específico para eliminação do parasita obteve-se um exemplar de Taenia $s p$. Este foi encaminhado ao laboratório e sua morfologia foi confirmada por microscopia direta com base em Neves (2005). O parasito ficou armazenado sob refrigeração $\left(4^{\circ} \mathrm{C}\right)$ e imerso em uma solução contendo cloridrato de oxitetraciclina $500 \mathrm{mg}$ (Terramicina ${ }^{\circledR}$ ) e água destilada. O preparo do inóculo consistiu de lavagem das proglotes, dissecação com auxílio de lupa e centrifugação. Foi realizada contagem do número de ovos com auxílio de microscópio a partir da média da quantidade de ovos presentes em cinco amostras (gotas) do sedimento oriundo da centrifugação $(10 \mathrm{ul} /$ cada $)$.

Para inoculação experimental utilizou-se $1 \mathrm{ml}$ do inóculo que continha aproximadamente 120.000 ovos de Taenia saginata, diluídos em água destilada, e administrado por via oral com auxílio de sonda gástrica. Em seguida, foram fornecidos cerca de $500 \mathrm{ml}$ deágua através da sonda, garantindo que todos os ovos presentes na alíquota fossem totalmente ingeridos. Nesse experimento foram selecionados nove bovinos machos, de raça mestiça holandês- 
zebu, com aproximadamente seis meses de idade, e mantidos em ambiente livre de contaminação por cisticercos, evitando assim reinfecção dos animais.

\section{Obtenção das amostras de soro}

O presente estudo foi realizado com amostras de soro bovino pertencentes a quatro grupos distintos. O grupo 1 foi composto por amostras de sangue de nove bovinos procedentes de uma propriedade sem histórico de cisticercose e que foram infectados experimentalmente. As amostras foram coletadas mensalmente, iniciando no dia 0 (data da inoculação) e finalizando com 14 meses pósinfecção. As amostras foram coletadas utilizando-se a seguinte ordem: dia 0 até 5 meses pós-infecção $(n=9), 6$ meses $(n=8), 7$ meses $(n=7), 8$ meses $(n=6)$, 9 meses $(n=5), 10$ meses $(n=4), 11$ meses $(n=4), 12$ meses $(n=3), 13$ meses $(n=2), 14$ meses $(n=1)$, num total de 93 amostras de soro.

$\mathrm{O}$ material foi dessorado e estocado a $-20^{\circ} \mathrm{C}$ com vistas à sua utilização nos ensaios laboratoriais de acordo com a metodologia empregada por Monteiro (2004). Todos os animais pertencentes a esse grupo foram abatidos em um matadouro-frigorífico, de acordo com as normas técnicas do Serviço de Inspeção Federal (BRASIL, 1971). Os animais foram rigorosamente inspecionados, examinando os tecidos inspecionados rotineiramente nas linhas de inspeção post-mortem para pesquisa de cisticercos (coração, língua, músculos mastigatórios), e outras áreas consideradas não rotineiras para inspeção representadas por quatro cortes comerciais de carnes, obtidos de meia carcaça, localizados nos quartos dianteiro e traseiro, sendo esses o acém, a paleta, a alcatra e o contra-filé. Ainda foram examinados o diafragma e seus pilares, esôfago e o fígado.

O grupo 2 foi composto de um total de 201 amostras de animais naturalmente infectados, cujo diagnóstico da cisticercose foi realizado durante a inspeção post-mortem conduzida na rotina de três matadouros-frigoríficos comerciais supervisionados por serviço de inspeção federal localizados nos municípios de Colatina-ES $(\mathrm{n}=122)$, ContagemMG ( $n=32)$ e Muriaé- MG ( $n=3)$, e um matadourofrigorífico supervisionado pelo serviço de inspeção estadual em Colatina-ES ( $\mathrm{n}=44)$.

No grupo 3, constitui-se de 26 amostras de bovinos abatidos em matadouro comercial, que foram negativos para cisticercose e outras doenças durante inspeção post-mortem de rotina. Estes soros-controle foram utilizados para a determinação do ponto de corte 1 .

Já as amostras de soro do grupo 4 foram obtidas de oito bovinos criados em isolamento e mantidos sob condições controladas, tratando-se de animais não portadores de cisticercos após o abate. Estes soros-controle foram utilizados para a determinação do ponto de corte 2 .

\section{Teste ELISA indireto}

As placas de poliestireno foram sensibilizadas com os antígenos diluídos em solução tamponada carbonato-bicarbonato $0,5 \mathrm{M}$ pH 9,6 estocadas a $37^{\circ} \mathrm{C}$ durante 1 hora. Após três lavagens em solução salina contendo $0,05 \%$ de tween-20, foi realizado o bloqueio dos sítios reativos (leite desnatado a $5 \%$ em PBS pH 7,4), durante 1 hora a $37^{\circ} \mathrm{C}$. Novas lavagens foram realizadas e as amostras foram diluídas em leite desnatado a 1\% em PBS pH 7,4 e a placa incubada por 30 minutos a $37^{\circ} \mathrm{C}$. Após lavagens, foi adicionado o anticorpo conjugado $\operatorname{IgG}$ (A5295, Sigma Chemical Co., St Louis, MO, USA) (1:5.000), e repetidos os procedimentos de incubação e lavagem. A reação foi revelada com solução de dihidrocloreto de o-fenilendiamina (OPD) P8287 (Sigma Chemical Co.; St Louis, MO, USA) a $0,1 \%$ e $\mathrm{H}_{2} \mathrm{O}_{2}, 0,003 \%$ em tampão citrato-fosfato $0,2 \mathrm{M}$ $\mathrm{pH} 5,0$, durante um período de incubação de 5 minutos. A reação foi bloqueada com $\mathrm{H}_{2} \mathrm{SO}_{4} 4 \mathrm{~N}$. As leituras foram realizadas em espectrofotômetro com comprimento de onda a 492nm. A quantidade de reagentes aplicados à placa se manteve em $100 \mu 1$, exceto para a solução bloqueadora, $200 \mu 1$. 
Critérios de interpretação e análise dos resultados do ELISA

Os soros foram analisados pelo teste ELISA em triplicata obtendo-se a média das DO. Os valores de DO obtidos foram ajustados com referência a uma placa padrão, sendo o fator de correção calculado conforme Passos (1993) e citado por Portela (2000).

$\mathrm{Na}$ expressão da positividade e negatividade dos resultados pelo teste ELISA, foi considerado o ponto de corte, representado pela D.O. média obtida na análise dos soros-controle negativos, acrescida de dois e três desvios-padrão.

As análises das variáveis em relação concordância entre período pós-infecção com critérios estabelecidos para ponto de corte (ponto de corte $1+2$ ou 3 SD e ponto de corte $2+2$ ou 3 $\mathrm{SD})$, foram calculadas pelo teste do Qui-quadrado $(\mathrm{p}<0,05)$.

\section{Comitê de ética}

As normas de conduta para o uso de animais em pesquisa do Comitê de Ética do uso de Animais da Universidade Federal de Viçosa foram seguidas, conforme o Processo CEUA/UFV n²0/2011.

\section{Resultados}

A partir do total de 93 amostras dos animais do grupo 1, 52 amostras ficaram acima do ponto de corte 1 (obtido através da média da densidade óptica dos soros-controle de animais negativos a inspeção de rotina) adicionados de 2 desvios-padrão (SD), sugestivo de animais positivos para a cisticercose, sendo que a sensibilidade do teste ficou em 55,9\%. Contudo, utilizando o ponto de corte 2 (densidades ópticas dos soros-controle pertencentes aos animais negativos para a cisticercose e criados em isolamento), somente 8 amostras ficaram abaixo do ponto de corte, sugestiva de animais negativos para a cisticercose, obtendo-se $92,5 \%$ de sensibilidade do teste ELISA, sendo que a especificidade do teste ficou em 100\% para ambos casos.

Ao analisar o ponto de corte 1 e 2 adicionados de $3 \mathrm{SD}$, foi possível constatar que do total de amostras do grupo 1, 29 ficaram acima do ponto de corte obtendo uma sensibilidade de $31,2 \%$ do teste. Já quando analisado o ponto de corte 2, somente 13 apresentaram-se negativas, tendo uma sensibilidade de $86 \%$ (Tabela 1 ).

Tabela 1. Frequência de resultados positivos e negativos para cisticercose ao teste ELISA aplicado em bovinos infectados experimentalmente de acordo com os resultados do exame anátomo-patológico realizado após o abate, considerando dois diferentes pontos de corte, utilizando-se de 2 e 3 desvios-padrão.

\begin{tabular}{|c|c|c|c|c|c|c|c|}
\hline \multicolumn{8}{|c|}{ Exame anátomo-patológico } \\
\hline & \multicolumn{3}{|c|}{2 desvios-padrão } & \multicolumn{4}{|c|}{3 desvios-padrão } \\
\hline & Ponto de corte $1^{*}$ & \multicolumn{2}{|c|}{ Ponto de corte $2 *$} & \multicolumn{2}{|c|}{ Ponto de corte $1^{*}$} & \multicolumn{2}{|c|}{ Ponto de corte $2 *$} \\
\hline Elisa & + & + & - & + & - & + & - \\
\hline+ & 52 & 85 & 0 & 29 & 0 & 80 & 0 \\
\hline- & 41 & 8 & - & 64 & - & 13 & - \\
\hline Total & 93 & 93 & - & 93 & - & 93 & - \\
\hline
\end{tabular}

*Ponto de corte 1 - bovinos abatidos em matadouro-frigorífico e negativos para cisticercose através do exame anátomo-patológico. Ponto de corte 2 - bovinos negativos criados em isolamento.

Fonte: Elaboração dos autores. 
Com relação ao grupo 2, do total de 201 amostras, 25 se apresentaram positivas para a cisticercose através do ELISA utilizando o ponto de corte 1 adicionados de 2 desvios-padrão. Nessas condições o valor da sensibilidade do teste quando comparado ao exame post-mortem ficou em $12 \%$. Contudo utilizando o ponto de corte 2 , adicionados de 2 desvios-padrão, foi possível detectar 49 animais positivos, perfazendo uma sensibilidade de $24,4 \%$. A especificidade do ELISA em ambos casos foi de
100\% (Tabela 2). Ao utilizar os mesmos critérios para seleção do ponto de corte 1 e 2, contudo adicionando 3 SD, pôde-se observar que do total de amostras somente 4 apresentaram-se como positivas para o ponto de corte 1 (sensibilidade de 1,99\%), e para o ponto de corte 2 , foi possível confirmar 29 amostras positivas (sensibilidade 14,4\%). De acordo com Pinto et al. (2000) quando o ponto de corte é aumentado para 3SD é previsível a queda da sensibilidade do teste.

Tabela 2. Frequência de resultados positivos e negativos para cisticercose ao teste ELISA aplicado em bovinos infectados naturalmente de acordo com os resultados do exame anátomo-patológico realizado após o abate, considerando dois diferentes pontos de corte, utilizando-se de 2 e 3 desvios-padrão.

\begin{tabular}{ccccccccc}
\hline & \multicolumn{9}{c}{ Exame anátomo-patológico } & \multicolumn{3}{c}{3 desvios-padrão } \\
& \multicolumn{4}{c}{ Ponto de corte $1^{*}$} & \multicolumn{2}{c}{ Ponto de corte $2^{*}$} & Ponto de corte $1^{*}$ & Ponto de corte $2^{*}$ \\
Elisa & + & - & + & - & + & - & + & - \\
\hline+ & 25 & 0 & 49 & 0 & 4 & 0 & 29 & 0 \\
- & 176 & 34 & 152 & 34 & 197 & 34 & 172 & 34 \\
Total & 201 & 34 & 201 & 34 & 201 & 34 & 201 & 34 \\
\hline
\end{tabular}

*Ponto de corte 1 - bovinos abatidos em matadouro-frigorífico e negativos para cisticercose através do exame anátomo-patológico. Ponto de corte 2 - bovinos negativos criados em isolamento.

Fonte: Elaboração dos autores.

O limiar de detecção da cisticercose pelo ELISA em relação ao número de cisticercos presentes nos animais foi de 1 cisticerco situado nos locais de inspeção de rotina para animais naturalmente infectados, e 2 cisticercos em animais experimentalmente infectados. Vale ressaltar que a detecção de cisticercos é realizada em musculaturas pré-definidas durante inspeção de rotina, não excluindo a presença de cisticercos em outras musculaturas não inspecionadas no caso de animais naturalmente infectados, e com relação ao grupo experimentalmente infectados, nenhum dos animais apresentou somente 1 cisticerco nas áreas pesquisadas provavelmente devido à alta carga parasitária inoculada.

\section{Discussão}

As taxas de sensibilidade encontradas foram superiores utilizando os critérios para seleção do ponto de corte 2 quando comparado ao ponto de corte 1. A diferença nas taxas de sensibilidade encontradas entre animais do grupo 1 e 2 é devido a magnitude da infecção, sendo que, em animais naturalmente infectados normalmente é mais branda quando comparada a animais infectados experimentalmente, o que também dificulta o diagnóstico sorológico. De acordo com Smith, Snowdon e Finlay (1991) os baixos níveis de anticorpos produzidos em infecções leves dificultam a seleção de um ponto de corte e a interpretação dos achados em testes sorológicos como o ELISA, sobretudo quando proveniente de animais monocisticercósicos (THOMAZ-SOCCOL et al., 2010). 
Os resultados reforçam a importância da origem do soro controle-negativo, mostrando a sua interferência no desempenho do ELISA indireto. Vale ressaltar que a utilização de 2 ou 3 SD como critério de ponto de corte é dependente do objetivo dos ensaios, visto que, a utilização de 3 SD é mais apropriado para fins de diagnóstico e 2 SD para testes de triagem ou seleção (PINTO et al., 2000). Paulan et al. (2013) relatam também a correlação entre ponto de corte e taxa de sensibilidade do ELISA.
No $1^{\circ} \mathrm{e} 2^{\circ}$ mês pós-infecção, seis dos nove bovinos experimentalmente infectados apresentaram-se como positivos ao ELISA utilizando o ponto de corte 1 adicionados de 2 SD. Contudo no $3^{\circ}$ mês pósinfecção somente 4 animais apresentaram títulos positivos, e no $4^{\circ}$ mês o número foi reduzido para 2 animais (Tabela 3). De acordo com Minozzo et al. (2004), o fato dos animais infectados desenvolverem anticorpos, mas no curso da infecção os níveis dos mesmos poderem cair abaixo do ponto de corte, mostra que o teste poderia não detectar alguns animais em fase crônica da doença.

Tabela 3. Número de amostras positivas no teste ELISA dos nove bovinos infectados experimentalmente, de acordo com o período pós-infecção (meses) e critério de ponto de corte.

\begin{tabular}{ccccc}
\hline \multirow{2}{*}{ Período pós-infecção } & \multicolumn{2}{c}{ Ponto de corte 1* } & \multicolumn{2}{c}{ Ponto de corte 2* } \\
\cline { 2 - 5 } & 2 SD & 3 SD & 09 & 3 SD \\
\hline 5 & 05 & 05 & 09 & 07 \\
6 & 06 & 05 & 09 & 08 \\
7 & 06 & 03 & 07 & 07 \\
8 & 04 & 01 & 07 & 07 \\
9 & 03 & 03 & 07 & 06 \\
11 & 05 & 02 & 08 & 08 \\
12 & 06 & 03 & 07 & 07 \\
13 & 05 & 02 & 05 & 05 \\
14 & 03 & 02 & 13,682 & 11,454 \\
$\chi^{2}$ & 17,485 & 10,579 & 0,474 & 0,650 \\
p & 0,231 & 0,719 &
\end{tabular}

$\mathrm{SD}=$ Desvio Padrão. *Ponto de corte 1 - bovinos abatidos em matadouro-frigorífico e negativos para cisticercose através do exame anátomo-patológico. *Ponto de corte 2 - bovinos negativos criados em isolamento. $\chi^{2}=$ resultado do qui-quadrado, $\mathrm{p}=$ valor estatístico do teste.

Fonte: Elaboração dos autores.

Ao comparar individualmente os critérios estabelecidos para o ponto de corte 1 adicionados de 2 desvios-padrão, através do teste de Marascuilo, foi encontrado diferença estatística significante $(p<0,05)$ somente entre o período de 6-11/13/14 e 1011/13/14 meses pós-infecção, tratando-se contudo, de casos isolados que ocorreram provavelmente devido ao baixo número de animais amostrados nesses períodos. Entretanto não foi encontrada diferença estatística $(p>0,05)$ pelo teste do quiquadrado ao comparar os períodos pós-infecção com os resultados de positividade no ELISA.
Somado a esse fato, ao analisar as amostras de sangue coletadas no momento do abate dos nove animais, seis apresentaram valores de densidade óptica abaixo do ponto de corte estabelecido no teste ELISA sugestivo de animais negativos para cisticercose, contudo ao exame post-mortem foram recuperados cisticercos de todos os seis animais (Tabela 4). De acordo com Flisser, Pérez-Montfort e Larralde (1979) a ausência de anticorpos não pode descartar a ausência da doença, sendo que a resposta humoral contra a cisticercose pode ser curta ou baixa. Mesmo com esses achados, no 
presente estudo não foi encontrado correlação direta entre carga parasitária e resposta imunológica. Esse fato demonstra que a utilização isolada do teste
ELISA para diagnóstico da cisticercose no campo ainda pode apresentar deficiências, sendo de grande importância a associação do método sorológico com o macroscópico.

Tabela 4. Resultado do teste ELISA em soros de bovinos infectados experimentalmente por animal, período pósinfecção (meses), número de cisticercos encontrados durante o abate e critério de ponto de corte.

\begin{tabular}{|c|c|c|c|c|c|c|}
\hline \multirow{2}{*}{ Animal } & \multirow{2}{*}{$\begin{array}{l}\text { Período pós- } \\
\text { infecção }\end{array}$} & \multirow{2}{*}{ Cisticercos } & \multicolumn{2}{|c|}{ Ponto de corte $1^{*}$} & \multicolumn{2}{|c|}{ Ponto de corte $2 *$} \\
\hline & & & $2 \mathrm{SD}$ & $3 \mathrm{SD}$ & $2 \mathrm{SD}$ & $3 \mathrm{SD}$ \\
\hline 39 & 5 & 05 & $\mathrm{~N}$ & $\mathrm{~N}$ & $\mathrm{P}$ & $\mathrm{P}$ \\
\hline 38 & 6 & 32 & $\mathrm{P}$ & $\mathrm{N}$ & $\mathrm{P}$ & $\mathrm{P}$ \\
\hline 33 & 7 & 53 & $\mathrm{P}$ & $\mathrm{P}$ & $\mathrm{P}$ & $\mathrm{P}$ \\
\hline 40 & 8 & 04 & $\mathrm{~N}$ & $\mathrm{~N}$ & $\mathrm{P}$ & $\mathrm{P}$ \\
\hline 32 & 9 & 50 & $\mathrm{P}$ & $\mathrm{P}$ & $\mathrm{P}$ & $\mathrm{P}$ \\
\hline 37 & 11 & 48 & $\mathrm{~N}$ & $\mathrm{~N}$ & $\mathrm{P}$ & $\mathrm{P}$ \\
\hline 31 & 12 & 37 & $\mathrm{~N}$ & $\mathrm{~N}$ & $\mathrm{P}$ & $\mathrm{P}$ \\
\hline 36 & 13 & 26 & $\mathrm{~N}$ & $\mathrm{~N}$ & $\mathrm{P}$ & $\mathrm{P}$ \\
\hline 35 & 14 & 02 & $\mathrm{~N}$ & $\mathrm{~N}$ & $\mathrm{P}$ & $\mathrm{P}$ \\
\hline
\end{tabular}

$\mathrm{SD}=$ Desvio Padrão. $\mathrm{N}=$ Negativo; $\mathrm{P}=$ Positivo.

*Ponto de corte 1 - bovinos abatidos em matadouro-frigorífico e negativos para cisticercose através do exame anátomo-patológico. *Ponto de corte 2 - bovinos negativos criados em isolamento.

Fonte: Elaboração dos autores.

Atualmente através de pesquisas emprega-se a utilização associada do exame anátomo-patológico realizado em matadouros-frigoríficos com a utilização de testes sorológicos como o ELISA, sendo importante não somente para diagnóstico da doença, mas podendo servir como uma ferramenta epidemiológica fornecendo dados da prevalência, conhecimento das áreas de risco e acompanhamento da sanidade do rebanho abatido provenientes de áreas endêmicas.

\section{Conclusões}

O esquema de padronização do teste ELISA pode variar de acordo com o interesse de sua aplicação. Deve-se considerar um equilíbrio entre sensibilidade e especificidade do teste, sendo que, ao utilizar o ponto de corte calculado com amostras de soro de animais negativos para cisticercose e mantidos sob condições controladas, aumenta significativamente a sensibilidade do teste.

\section{Agradecimentos}

Os autores gostariam de agradecer ao $\mathrm{CNPq}$ e FAPEMIG pelo suporte financeiro.

\section{Referências}

ALLEPUZ, A.; GABRIEL, S.; DORNY, P.; NAPP, S.; JANSEN, F.; VILAR, M. J.; VIVES, L.; PICART, L.; ORTUNO, A.; GUTIÉRREZ, J.; CASAL, J. Comparison of bovine cysticercosis prevalence detected by antigen ELISA and visual inspection in the North East of Spain. Research Veterinary Science, v. 92, n. 3, p. 393-395, 2012.

BAVIA, M. E.; CARNEIRO, D. D. M. T.; CARDIM, L. L.; SILVA, M. M. N.; MARTINS, M. S. Estatística espacial de varredura na detecção de áreas de risco para a cisticercose bovina no estado da Bahia. Arquivo Brasileiro de Medicina Veterinária e Zootecnia, Belo Horizonte, v. 64, n. 5, p. 1200-1208, 2012.

BRASIL. Decreto 30.691 de 29/03/52, alterado pelos decretos 1.255 de 25/06/1962, 1236 de 02/09/1994, 1812 de 08/02/1996 e 2244 de 04/06/1997. Dispõe sobre o regulamento de inspeção industrial e sanitária de 
produtos de origem animal. Diário Oficial [da] União, Ministério da Agricultura, Brasília, DF, 05 jun. 1997, Seção 1, p. 11555.

Ministério da Agricultura, Pecuária e Abastecimento (MAPA). Inspeção de carnes: padronização de técnicas, instalações e equipamentos. Brasília, DIPOA/DICAR, 1971. 183 p. Tomo I: Bovinos.

DORNY, P.; VERCAMMEN, F.; BRANDT, J.; VANSTEENKIST, E. W.; BERKVENS, D.; GEERTS, S. Seroepidemiological study of Taenia saginata cysticercosis in Belgian cattle. Veterinary Parasitology, Amsterdam, v. 88, n. 1-2, p. 43-49, 2000.

FERNANDES, J. O. M.; SILA, C. L. S.; BORGES, J. H. R.; PEGAINE, J. C.; COELHO, R. V. Prevalência da cisticercose bovina em animais abatidos em estabelecimento sob regime de Inspeção Federal no município de Andradina-SP. Revista Ciências Agrárias e da Saúde, Andradina, v. 2, n. 1, p. 14-17, 2002.

FLISSER, A.; PÉREZ-MONTFORT, R.; LARRALDE, C. The immunology of human and animal cysticercosis: a review. Bulletin of the World Health Organization, v.57, n. 5, p. 839-856, 1979.

GEERTS, S.; KUMAR, V.; CEULEMANS, F.; MORTELMANS, J. Serodiagnosis of Taenia saginata cysticercosis in experimentally and naturally infected cattle by enzyme linked immunosorbent assay. Research Veterinary Science, v. 30, n. 3, p. 288-293, 1981.

GUIMARÃES-PEIXOTO, R. P. M.; SOUZA, W. K.; PINTO, P. S. A.; SANTOS, T. O. Distribuição e identificação das regiões de risco para a cisticercose bovina no Estado do Paraná. Revista Pesquisa Veterinária Brasileira, Seropédica, v. 32, n. 10, p. 975-979, 2012.

KYVSGAARD, N. C.; ILSØE, B.; HENRIKSEN, S. A.; FELD, N. C.; NANSEN, P. Evaluation of an enzymelinked immunosorbent assay (ELISA) for detection of Taenia saginata cysticercosis in cattle. Acta Veterinaria Scandinavica, v. 32, n. 2, p. 233-241, 1991.

MINOZZO, J. C.; THOMAZ-SOCCOL, V.; OlORTEGUi, C. C.; SOARES, V. E.; COSTA, A. J. Teste Imunoenzimático (Enzyme-Linked Immunosorbent Assay) para diagnóstico da cisticercose bovina e estudo da cinética de produção de anticorpos contra-Cysticercus bovis. Ciência Rural, Santa Maria, v. 34, n. 3, p. 857-864, 2004

MONTEIRO, L. L. Emprego de antígenos de larvas de Taenia crassiceps e Taenia solium em teste ELISA para diagnóstico da cisticercose bovina. 2004. Dissertação (Mestrado em Medicina Veterinária) - Universidade Federal de Viçosa, Viçosa, MG.
MONTEIRO, L. L.; PINTO, P. S. A.; BEVILACQUA, P. D.; SANTOS, I. F.; MAIA, A. A. M.; DIAS, F. S. Ensaios de padronização do teste ELISA para diagnóstico da cisticercose bovina utilizando antígenos de larva de Taenia crassiceps. Revista Brasileira de Ciências Veterinárias, Niterói, v. 15, n. 1, p. 45-49, 2008.

NEVES, D. P. Parasitologia humana. 11. ed. São Paulo: Atheneu, 2005. $494 \mathrm{p}$.

OGUNREMI, O.; BENJAMIN, J. Development and field evaluation of a new serological test for Taenia saginata cysticercosis. Veterinary Parasitology, Amsterdam, v. 169, n. 1-2, p. 93-101, 2010.

PASSOS, L. M. F. Immunological studies on bovine babesiosis with particular reference to Brazil using "in vitro" culture- derived antigens. 1993. Tese (PhD em Tropical Veterinary Medicine) - Center of Tropical Veterinary Medicine, Edinburgh University, Edinburg.

PAULAN, S. C.; GONZÁLES, R. M. H.; PERALTA, L. A.; OLIVEIRA, J. C. V.; BIONDI, G. F.; CONDE, E. C.; PARKHOUSE, R. M. E.; NUNES, C. M. Usefulness of serological ELISA assay for Taenia saginata to detect naturally infected bovines. Revista Brasileira Parasitologia Veterinária, Jaboticabal, v. 22, n. 2, p. 270275, 2013.

PINTO, P. S. A.; MONTEIRO, L. L.; MINOZZO, J. C. Influência de diferentes grupos de soros-controle no diagnóstico da cisticercose bovina pelo teste ELISA. Revista Ceres, Viçosa, MG, v. 53, n. 309, p. 574-579, 2006.

PINTO, P. S. A.; VAZ, A. J.; GERMANO, P. M. L.; NAKAMURA, P. M. ELISA test for the diagnosis of cysticercosis in pigs using antigens of Taenia solium and Taenia crassiceps cysticerci. Revista Instituto Medicina Tropical, São Paulo, v. 42, n. 2, p. 71-79, 2000.

PORTELA, R. W. D. Comparação experimental de três peptídeos sintéticos como imunógenos no controle do carrapato Boophilus microplus (Canetrini, 1887). 2000. Dissertação (Mestrado em Medicina Veterinária) Universidade Federal de Viçosa, Viçosa, MG.

QUEIROZ, R. P. V.; SANTOS, W. L. M.; BARBOSA, H. V.; SOUZA, R. M.; SANTOS FILHO, A. M. P. A importância do diagnóstico da cisticercose bovina. Revista Higiene Alimentar, São Paulo, v. 14, n. 77, p. 12$15,2000$.

REZENDE, R. B. C.; FERNADEZ, A. T.; COSTA, F.; SILVA, T. J. P. Ocorrência de cisticercose em bovinos abatidos clandestinamente no município de Silva Jardim, RJ. Revista Higiene Alimentar, São Paulo, v. 21, n. 140, p. 103-109, 2006. 
ROSSI, G. A. M.; GRISÓLIO, A. P. R.; PRATA, L. F.; BURGUER, K. P.; HOPPE, E. G. L. Situação da cisticercose bovina no Brasil. Semina: Ciências Agrárias, Londrina, v. 35, n. 2, p. 927-938, 2014.

SILVA, A. V. M. Teníase e cisticercose. In: NEVES, D. P.; LINARDI, P. M.; VITOR, R. W. A. Parasitologia humana. 11. ed. São Paulo: Editora Atheneu, 2005. p. 227-237.

SMITH, H. J.; SNOWDON, K. E.; FINLAY, R. C. Serological diagnosis of cysticercosis by enzyme-linked immunosorbent assay in experimentally infected cattle. Canadian Journal of Veterinary Research, Ottawa, v. 55, n. 3, p. 274-276, 1991.
SMITH, H. J.; SNOWDON, K. E.; GREGORY, D.; FINLEY, G. G. Assessment of an enzyme-linked immunosorbent assay using a Taenia hydatigena fraction antigen in the diagnosis of cysticercosis in cattle. Canadian Journal of Veterinary Research, Ottawa, v. 54, n. 2, p. 299-300, 1990.

THOMAZ-SOCCOL, V.; SOUZA, V. K.; PESSOA, O. L.; MINOZZO, J. C.; PESSOA-SILVA, M. C.; PEIXOTO, R. P. M. G.; MOURA, J. F. Archives of Veterinary Science, Curitiba, v. 15, n. 2, p. 77-85, 2010. 